\title{
Rapunzel Syndrome in a 7-year-old Egyptian Girl with Primary Biliary Cirrhosis: A case Report and Literature Review
}

\author{
Abdel-Azeem M El-Mazary ${ }^{1^{*}}$, Magdy F. Ahmed ${ }^{2}$, Ayman Hasanin $^{3}$ and Walid M Abdel-Hamed ${ }^{4}$ \\ ${ }^{1}$ Associate Professor, Departments of Pediatrics, Minia University, Egypt \\ ${ }^{2}$ Tropical Medicine, Minia University, Egypt \\ ${ }^{3}$ Professor, Surgery,Minia University, Egypt \\ ${ }^{4}$ Lecturer, Clinical-Pathology, Minia University, Egypt,
}

*Corresponding author: Abdel-Azeem M El-Mazary, Departments of Pediatrics, Minia University, Egypt; Tel: 002-01224315723; E-Mail: abdelazeemhemed@yahoo.com

Received Date: July 1, 2014, Accepted Date: September 23, 2014, Published Date: September 30, 2014

Copyright: (C) 2014, Abdel-Azeem M. El-Mazary et al., This is an open-access article distributed under the terms of the Creative Commons Attribution License, which permits unrestricted use, distribution, and reproduction in any medium, provided the original author and source are credited.

\begin{abstract}
Introduction: bezoars are masses formed by the accumulation of intraluminal nondigestible substances that can lead to obstruction of the stomach and the small intestine. The anatomical changes in the gastrointestinal tract are known to cause bezoar formation. The so-called Rapunzel syndrome is the extension of the bezoars down to the duodenum and the jejunum, which is a rare condition. This may occur in subjects with mental retardation and/or psychiatric disorders.

Case presentation: we present a 7-year-old female with primary biliary cirrhosis who was admitted to our department with hematemesis, loss of weight and fatigue complaints along the last 6 months, in whom a giant trichobezoar was identified through endoscopy which completely filled the stomach and duodenum causing partial obstruction and needed surgical interference for removal and psychiatric therapy. We believe that -after MEDLINE search along the last 10 years- this is the first Egyptian case presentation of Rapunzel syndrome in a child with autoimmune liver disease (primary biliary cirrhosis) and trichotillomania presented at very young age. The link between autoimmune liver diseases and neuropsychiatry disorders is still poorly understood and this case report may help us to understand the link between the two disorders. Conclusions: trichobezoars should be considered as a differential diagnosis in children complaining of recurrent abdominal pain with epigastric mass and progressive weight loss. The link between autoimmune liver diseases and neuropsychiatry disorders is still poorly understood and this case may help us to understand the link between the two disorders. It is an original case report of interest to pediatricians especially gastroenterology, hepatology and neuropsychiatry specialists.
\end{abstract}

Keywords: Rapunzel; Trichobezoar; Biliary; Cirrhosis; Female; Egyptian

\section{Introduction}

A bezoar is an accumulation of food or foreign material in the intestinal tract. The term bezoar derives from the Arabic word Badzehr, which means antidote [1]. Bezoars were used as antidotes against many diseases like leprosy, snake bite, plague and epilepsy by physicians from 12 th to 18 th centuries [2]. It can be classified according to the primary constituent as trichobezoar (hairball), phytobezoar (food particles), trichphytobezoar (mixed), mycobezoar (fungal agglomerations), lactobezoar (milk component), or pseudobezoar [3]. Trichobezoars are the commonest type of bezoars and it is often associated with trichotillomania (hair pulling) and/or trichophagia (hair swallowing). Occasionally, trichobezoars have a tail that extends to the cardia, pylorus, and duodenum, or even further to the jejunum and ileum forming what is called Rapunzel syndrome [4].

\section{Case Presentation}

A 7-year-old Hamitic female with a low socio-economic level admitted to our department with an attack of hematemesis associated with recurrent abdominal pain, satiety exacerbated at meal times, pruritus, loss of weight, fatigue complaints as well as sleep disturbance along the last 6 months. The attack of hematemesis was the second attack while the first one occurred one year ago. There was recurrent dull aching pain mainly in the epigastric region not related to meals or physical activity. Her personal history revealed nothing significant except for the previous attack of hematemesis which passed without any search for medical advice. There was no past history of previous hospital admission, incubation, alcohol drinking by the family, drug intake, swimming in or use of water of rural canals. There was no history of blood transfusion and no prior history of early deaths, liver disease or autoimmunity existed in the family.

General examination revealed under built fully conscious, oriented, cooperative female child with depressed mood. Mild pallor and jaundice were present but no cyanosis. Normal vital signs for age and sex were present. There was no lymphadenopathy or generalized edema. Abdominal palpation revealed a mobile well-defined mass occupying the upper half of the abdomen. The mass was not tender and was firm in consistency. The spleen was enlarged three fingers below the costal margin but no hepatomegaly or ascites was present. Abdominal ultrasonography revealed shrunken liver and portal hypertension. Extensive workshops of investigations were done to reach to the diagnosis of shrunken liver and portal hypertension: A complete urine analysis revealed increased the bilirubin level while it 
Citation: Azeem M El-Mazary A, Ahmed FM, Hasanin A, Abdel-Hamed WM (2014) Rapunzel Syndrome in a 7-year-old Egyptian Girl with Primary Biliary Cirrhosis: A case Report and Literature Review. J Psychiatry 17: 1000155. doi:10.4172/2378-5756.1000155

Page 2 of 5

was negative for succiny lacetone $(0.38 \mathrm{mmol} / \mathrm{L})$ and Bilharzial ova. The stool analysis revealed no abnormalities. A complete blood count revealed hypochromic microcytic anemia $(\mathrm{Hb} 9 \mathrm{gm} / \mathrm{dL})$ with normal TLC $\left(10.2 / \mathrm{mm}^{3}\right)$ and platelets count $\left(270 / \mathrm{mm}^{3}\right)$. ESR (first hour 40$)$ and CRP $(28 \mathrm{mg} / \mathrm{dL})$ levels were mildly elevated. The renal function tests were normal (BUN $16 \mathrm{mg} / \mathrm{dL} \&$ creatinine $0.7 \mathrm{mg} /$ ). The liver function tests showed mildly elevated bilirubin (total $6.8 \mathrm{mg} / \mathrm{dL}$, direct $4.2 \mathrm{mg} / \mathrm{dL}$ ), alkaline phosphatase (700 IU/L), ALT (630 IU/L), AST (240 IU/L) and GGT (104 IU/L) levels. The Prothrombin time (30 seconds) and concentration (60\%) were mildly affected, while the levels of $\alpha$-feto protein $(40 \mu \mathrm{g} / \mathrm{L})$, ceruloplasmin $(30 \mathrm{mg} / \mathrm{dL})$ and $\alpha 1-$ antitrypsin $(210 \mathrm{mg} / \mathrm{dL})$ levels were normal. The laboratory tests excluded viral infections like (hepatitis virus A, B, C, human immunodeficiency virus, Epstein-Barr and cytomegalo virus). AntiBilharzial antibodies were negative. Anti-mitochondrial antibodies by indirect immunofluorescence (IIF) were positive (>1:360). Immunological testing for ANA, anti-smooth muscle and anti-LKM-1 antibodies were negative. Total serum IgG $(962 \mathrm{mg} / \mathrm{dL})$ and IgA (198 $\mathrm{mg} / \mathrm{dL})$ titres were normal; while IgM titer $(330 \mathrm{mg} / \mathrm{dL})$ was elevated. Upper gastrointestinal endoscopy was done for diagnosis of the cause of hematemesis and revealed an esophageal varices grade II and a trichobezoar occupying almost the whole gastric cavity extending through the pylorus to the duodenum (Figure.1). Two endoscopic trials for removal of the trichobezoar had been failed as it was possible to pull only few fibers of this huge ball of hair (Figure.2).

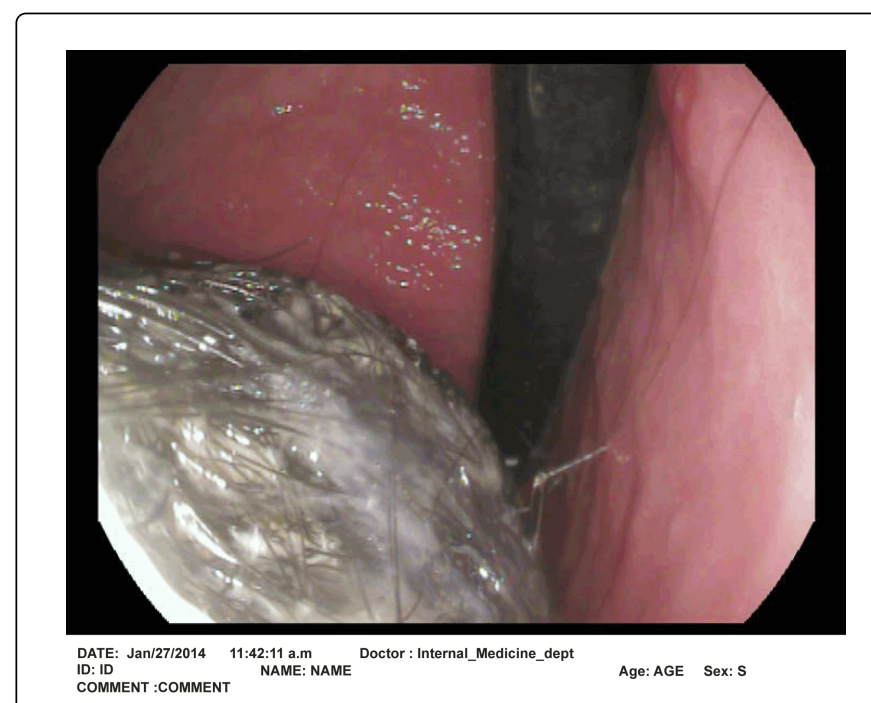

Figure1: Endoscopic picture for the trichobezoar.

The patient underwent surgery for gastrotomy. A huge trichobezoar was identified which took the shape of the stomach (Figure 3). The whole trichobezoar was removed which weighted 1200 grams. There was a long tail of hair extending through the pylorus into the proximal jejunum. By this feature the diagnosis was clear of a Rapunzel syndrome. The patient had an uneventful postoperative course and was discharged after 5 days. Postoperatively, the patient reported continuous ingestion of her own hair along the last year in addition to sleep disorders in the form of frequent insomnia and nightmares and mood disorder in the form of depressed mood. In our case the need for adequate regular follow-up in psychiatric as well as our departments had been emphasized and after several months' psychotherapy and pharmacotherapy, the patient is presently reported to have no hair-pulling events and normal sleep rhythm and mood.

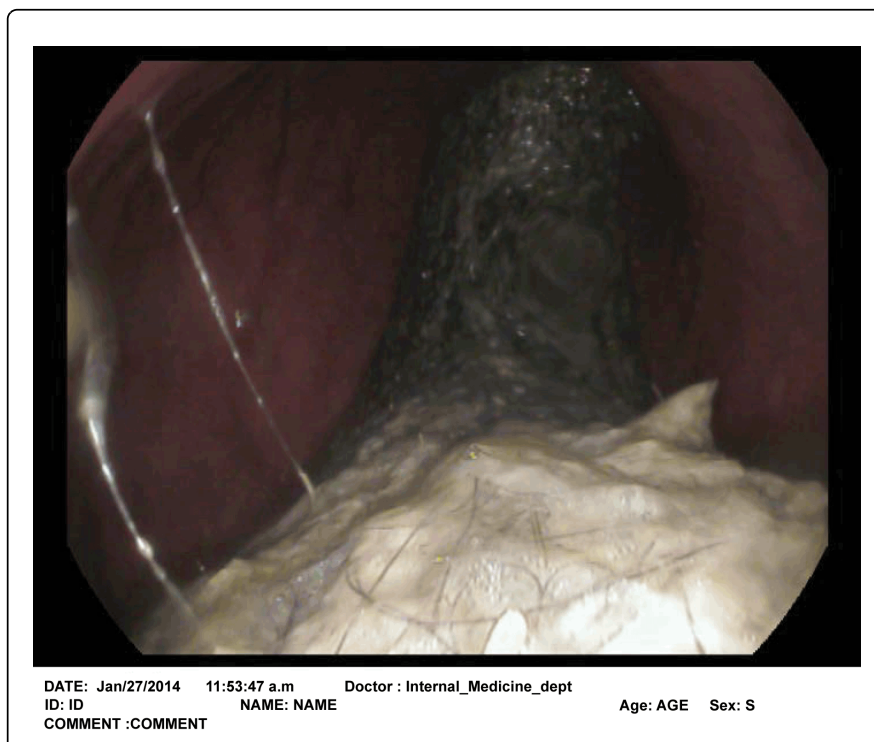

Figure 2: Endoscopic trial for removal the trichobezoar

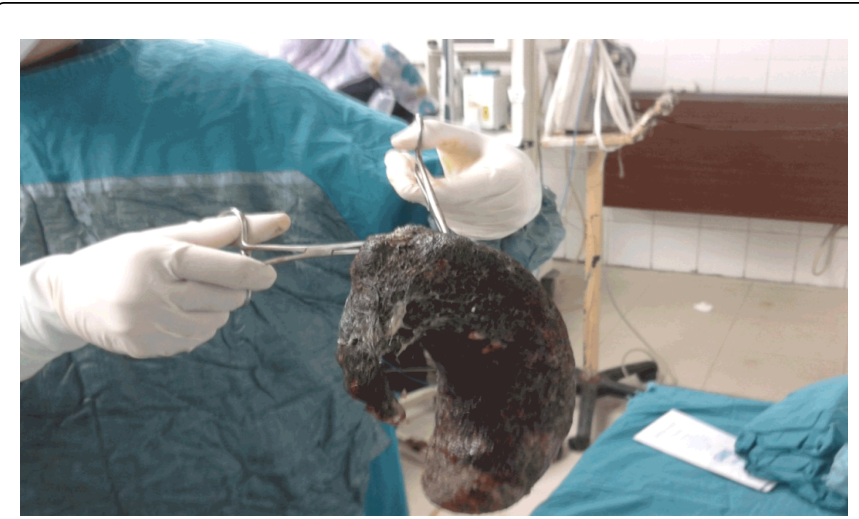

Figure 3: The whole trichobezoar after surgical removal

\section{Discussion}

Rapunzel syndrome is named after a tale written in 1812 by the Brothers Grimm about a young maiden, Rapunzel, with long hair who lowered her hair to the ground from a castle, which was a prison tower to permit her young prince to climb up to her window and rescue her. This syndrome was originally described by Vaughan et al. in 1968 [5]. Trichobezoars were first described from a post mortem by Swain in 1854 [6], and it is the most commonly encountered bezoar in humans. It is almost exclusively seen in young females, often associated with psychiatric problems [7]. The presentation in young age with hair extending down to the proximal jejunum may cause symptoms and signs mimic gastrointestinal infections and infestation especially in endemic areas [8]. Trichobezoars are usually black from denaturation of protein by acid, glistening from retained mucus and foul smelling from degradation of food residue trapped within it [9]. The presentation for trichobezoars usually occurs during the adulthood and rarely occurs in children, so we believe that our case is one of few 
cases all over the world presented by Rapunzel syndrome so early at this age [10-12].

Patients with Rapunzel syndrome usually presents with epigastric discomfort, pain, nausea, vomiting, satiety exacerbated at meal times, and/or manifestations of gastric outlet obstruction and most of these symptoms were consistent with our child. The recurrent abdominal pain in our case may be due to gastropathy related to portal hypertension and primary biliary cirrhosis, the impact of psychiatric disorder and the effect of trichobezoar itself $[13,14]$. The presentation of our child by two attacks of hematemesis, loss of weight, easily fatigability, pruritus and jaundice as well as the ultrasonography findings of shrunken liver and portal hypertension raised the possibility of liver cirrhosis [15-17]. After an extensive workshop of investigations; the diagnosis of primary biliary cirrhosis was established based on the clinical picture, sonographic findings (mentioned above) in addition to the disturbed liver functions (increased levels of bilirubin, alkaline phosphatase, and liver enzymes) and the positive anti-mitochondrial antibodies [15-19].

PBC is characterized by an immune-mediated destruction of intrahepatic bile ducts and the presence of high-titer antimitochondrial antibodies (AMA) [15-20]. Unlike other autoimmune liver diseases, typical features of $\mathrm{PBC}$ have rarely been reported in early childhood. The frequently reported pediatric autoimmune liver disorders include $\mathrm{AIH}$ types 1 and 2, and autoimmune sclerosing cholangitis (ASC) $[21,22]$. The youngest child previously described with PBC was a six year old female [23]. Here, we present a 7-yearEgyptian female child with a clinical picture of liver cirrhosis and portal hypertension with a high titer of AMA while the other auto antibodies for autoimmune hepatitis were negative. Our child reported continuous ingestion of her own hair (trichotillomania) along the last year in addition to sleep disorders in the form of frequent insomnia and nightmares and mood disorder in the form of depressed mood. This psychiatric disorder may be due to the low socioeconomic state of the her family as well as the large sized family which consists of 5 siblings and parents which delayed the search of medical advice in spite of recurrent complaining of recurrent abdominal pain and hematemesis along the last year.

The link between autoimmune liver diseases and neuropsychiatry disorders is still poorly understood and there were many studies tried to explore the existing evidence concerning neuropsychiatric symptomatology in patients with $\mathrm{PBC}$ (e.g. fatigue, cognitive impairment as well as mood and sleep disturbances) [24, 25]. Forton et al. [24] reported that the changes in the manganese level in blood and globus pallidus magnetisationmay be responsible for easily fatigability in patients with PBC. Both of urine and stool analysis were normal for Bilharzial ova and other parasitic infestations but it was positive for bilirubin which is consistent with the mild jaundice of our case. The hypochromic microcytic anemia of our child may be referred to the bad dietetic state of our child along the last year, the state of the liver cirrhosis, the psychological state of our child as well as the blood loss through the two hematemesis attacks. The mildly elevated bilirubin levels, mildly affected Prothrombin time and concentration, mildly elevated ESR and CRP levels; all of them reflected the inflammatory state of the liver secondary to primary biliary cirrhosis [17-19]. The negative hepatitis markers for $\mathrm{HBV}$ and $\mathrm{HCV}$ as well as other viral infections (mentioned before) excluded them as causes of chronic liver disease in our case [26].

Bilharziasis is a common cause of portal hypertension especially in Egypt and we excluded it through the negative history of swimming in or usage of water of rural canals and negative results of urine and stool analysis to Bilharzial ova and negative anti Bilharzial antibodies in blood [27]. The normal a1-Antitrypsin, ceruloplasmin, urinary succinylacetone and $a$-feto-protein levels excluded other possible causes of chronic liver disease like a1-antitrypsin deficiency, Wilson disease, Tyrosinemia and malignant disorders of the liver [22,28]. AMA are highly specific for PBC, and often precede the development of liver damage by several years, even in individuals who are asymptomatic and do not have any other evidence of chronic liver disease [29-31]. Ultrasound examination of the liver and biliary tree is obligatory in all cholestatic patients in order to differentiate intrahepatic from extrahepatic cholestasis. When the biliary system appears normal and serum AMA are present, no further radiologic workup is necessary [32,33]. A liver biopsy is not anymore regarded as mandatory for the diagnosis of $\mathrm{PBC}$ in patients with elevated serum markers of cholestasis and positive serum AMA [33]. The complications of the Rapunzel syndrome ranges from attacks of incomplete pyloric obstruction to rarely complete obstruction of the bowel to perforation to peritonitis and mortality [34,35]. Bleeding, perforation, protein losing enteropathies, steatorrhea, pancreatitis, appendicitis, and/or intussusceptions may occur [36-38]. We believe that -after MEDLINE search along the last 10 years- this is the first Egyptian case presentation of Rapunzel syndrome in a child with autoimmune liver disease (primary biliary cirrhosis) and trichotillomania presented at very young age (7-years). The link between autoimmune liver diseases and neuropsychiatry disorders is still poorly understood and this case report may help us to understand the link between the two disorders.

There are different lines of treatment for trichobezoar: If small, they may be removed endoscopically through biopsy devices, water jets, bezotomes [39]. Laparoscopic removal may be successful in some cases using LASER devices to fragment larger bezoars and lavaged out of the stomach $[40,41]$. Up till now surgical removal at laparotomy is the treatment of choice [42]. In our case two trials of endoscopic removal using biopsy devices were failed. Psychiatric follow-up is very important for successful treatment and prevention of the recurrence. This follow-up care should be extended to family members, who should be vigilant with patients [43]. No clear evidence-based practice guidelines for the treatment of patients with (trichotillomania) TTM are available till now. The behavioral approaches, including habitreversal therapy, have been shown to be effective. In habit-reversal therapy, patients learn to "substitute a different and more adaptive behavior". They practice movements such as those in knitting, crochet, and needlepoint that redirect their urges to pull their hair. Other approaches such as cognitive-behavioral treatment, negative practice, and variations of these interventions have been tried [44]. In adults, selective serotonin reuptake inhibitors (SSRIs) are the pharmacologic agents used most frequently in the treatment of patients with TTM. Other psychotropic agents including the tricyclic antidepressants, the antipsychotic medications, and mood-stabilizing (anticonvulsant) medications as well as clomipramine hydrochloride and fluoxetine hydrochloride have been used successfully in some patients [45-47].

Ursodeoxycholic acid $30 \mathrm{mg} / \mathrm{kg} /$ day for biliary cirrhosis [48], propranolol $10 \mathrm{mg} / \mathrm{kg} /$ day for portal hypertension [49], imipramine (a tricyclic antidepressant) for psychiatric problems and fat soluble vitamins were the main drugs prescribed for our child. Our case as well as her family had been advised for adequate regular follow-up in both psychiatry and our departments to ensure follow-up of the portal hypertension and the liver state as well as psychiatric and behavioral 
Citation: Azeem M El-Mazary A, Ahmed FM, Hasanin A, Abdel-Hamed WM (2014) Rapunzel Syndrome in a 7-year-old Egyptian Girl with Primary Biliary Cirrhosis: A case Report and Literature Review. J Psychiatry 17: 1000155. doi:10.4172/2378-5756.1000155

Page 4 of 5

therapy in the form of regular cognitive behavioral therapy group meeting.

\section{Conclusions}

Trichobezoars should be considered as a differential diagnosis in children complaining of recurrent abdominal pain with epigastric mass and progressive loss of weight especially if there are any psychiatric problems. Management almost always requires surgical interference. We present the first Egyptian case presentation of Rapunzel syndrome in a female child with autoimmune liver disease (primary biliary cirrhosis) and trichotillomania presented at very young age (7-years). The link between autoimmune liver diseases and neuropsychiatry disorders is still poorly understood and this case report may help us to understand the link between the two disorders.

\section{Consent}

Written informed consent was obtained from the patient's legal guardian(s) for publication of this case report and any accompanying images. A copy of the written consent is available for review by the Editor-in-Chief of this journal."

\section{Conflict of Interest}

The author(s) declare that they have no competing interests.

\section{Acknowledgements}

Great thanks to our patient and her family for their acceptance to publish this case report. Also we thank all staff members of Psychiatry department, Minia University for their psychiatric management and follow-up of our case.

\section{References}

1. Samad A, Ahmad M, Latif Z (1997) Bezoars: a review and report of two cases. Journal of the College of Physicians and Surgeons Pakistan 7: 263-265.

2. Khattak S and Asghar K (2004) Trichobezoars. Gomal Journal of Medical Sciences2: 25-26.

3. Mewa Kinoo S, Singh B (2012) Gastric trichobezoar: an enduring intrigue. Case Rep Gastrointest Med 2012: 136963.

4. Rabie ME, Arishi AR, Khan A, Ageely H, Seif El-Nasr GA, et al. (2008) Rapunzel syndrome: the unsuspected culprit. World J Gastroenterol 14 1141-1143.

5. Vaughan ED Jr, Sawyers JL, Scott HW Jr (1968) The Rapunzel syndrome. An unusual complication of intestinal bezoar. Surgery 63: 339-343.

6. Williams RS (1986) The fascinating history of bezoars. Med J Aust 145: 613-614.

7. Bouwer C, Stein DJ (1998) Trichobezoars in trichotillomania: case report and literature overview. Psychosom Med 60: 658-660.

8. Gonuguntla V, Joshi DD (2009) Rapunzel syndrome: a comprehensive review of an unusual case of trichobezoar. Clin Med Res 7: 99-102.

9. Lamerton AJ (1984) Trichobezoar: two case reports-a new physical sign. Am J Gastroenterol 79: 354-356.

10. Jain M, Solanki SL, Bhatnagar A, Jain PK (2011) An unusual case report of rapunzel syndrome trichobezoar in a 3-year-old boy. Int J Trichology 3: 102-104.

11. Ventura DE, Herbella FA, Schettini ST, Delmonte C (2005) Rapunzel syndrome with a fatal outcome in a neglected child. J Pediatr Surg 40: 1665-1667.
12. Kim JS1, Nam CW (2013) A case of rapunzel syndrome. Pediatr Gastroenterol Hepatol Nutr 16: 127-130.

13. Kaplan MM, Gershwin ME (2005) Primary biliary cirrhosis. N Engl J Med 353: 1261-1273.

14. Urrunaga NH1, Rockey DC2 (2014) Portal hypertensive gastropathy and colopathy. Clin Liver Dis 18: 389-406.

15. Talwalkar JA, Lindor KD (2003) Primary biliary cirrhosis. Lancet 362 . 53-61.

16. Heathcote EJ (2000) Management of primary biliary cirrhosis. The American Association for the Study of Liver Diseases practice guidelines. Hepatology 31: 1005-1013.

17. Heidelbaugh JJ, Bruderly M (2006) Cirrhosis and chronic liver failure: part I. Diagnosis and evaluation. Am Fam Physician 74: 756-762.

18. European Association for the Study of the Liver (2009) EASL Clinical Practice Guidelines: management of cholestatic liver diseases. J Hepatol 51: 237-267.

19. Invernizzi P, Selmi C, Gershwin ME (2010) Update on primary biliary cirrhosis. Dig Liver Dis 42: 401-408.

20. Mitchison HC, Bassendine MF, Hendrick A, Bennett MK, Bird G, et al. (1986) Positive antimitochondrial antibody but normal alkaline phosphatase: is this primary biliary cirrhosis? Hepatology 6: 1279-1284.

21. Dahlan Y, Smith L, Simmonds D, Jewell LD, Wanless I, et al. (2003) Pediatric-onset primary biliary cirrhosis. Gastroenterology 125: 1476-1479.

22. Mieli-Vergani G, Vergani D (2008) Autoimmune paediatric liver disease. World J Gastroenterol 14: 3360-3367.

23. Melegh B, Skuta G, Pajor L, Hegedüs G, Sumegi B (1998) Autoantibodies against subunits of pyruvate dehydrogenase and citrate synthase in a case of paediatric biliary cirrhosis. Gut 42: 753-756.

24. Forton DM, Patel N, Prince M, Oatridge A, Hamilton G, et al. (2004) Fatigue and primary biliary cirrhosis: association of globus pallidus magnetisation transfer ratio measurements with fatigue severity and blood manganese levels. Gut 53: 587-592.

25. Newton JL, Hollingsworth KG, Taylor R, El-Sharkawy AM, Khan ZU, et al. (2008) Cognitive impairment in primary biliary cirrhosis: symptom impact and potential etiology. Hepatology 48: 541-549.

26. Hsu EK, Murray KF (2008) Hepatitis B and C in children. Nat Clin Pract Gastroenterol Hepatol 5: 311-320.

27. Sarin SK, Khanna R2 (2014) Non-cirrhotic portal hypertension. Clin Liver Dis 18: 451-476.

28. Suchy FJ, Sokol RJ, Balistreri WF (2007) Liver diseases in children. 3rd ed. Cambridge University Press.

29. Bogdanos DP, Baum H, Vergani D (2003) Antimitochondrial and other autoantibodies. Clin Liver Dis 7: 759-777, vi.

30. Hu S, Zhao F, Wang Q, Chen WX (2014) The accuracy of the antimitochondrial antibody and the M2 subtype test for diagnosis of primary biliary cirrhosis: a meta-analysis. Clin Chem Lab Med .

31. Yamagiwa S, Kamimura H, Takamura M, Aoyagi Y (2014) Autoantibodies in primary biliary cirrhosis: recent progress in research on the pathogenetic and clinical significance. World J Gastroenterol 20: 2606-2612.

32. Hohenester S, Oude-Elferink RP, Beuers U (2009) Primary biliary cirrhosis. Semin Immunopathol 31: 283-307.

33. Flores A, Mayo MJ (2014) Primary biliary cirrhosis in 2014. Curr Opin Gastroenterol 30: 245-252.

34. Jensen AR, Trankiem CT, Lebovitch S, Grewal H (2005) Gastric outlet obstruction secondary to a large trichobezoar. J Pediatr Surg 40: 1364-1365.

35. Park JS, Kim HJ, Chung JY (2009) a case of trichobezoar with small bowel obstruction. Korean J Pediatr Gastroenterol Nutr 12: 230-234.

36. Jiledar, Singh G, Mitra SK (1996) Gastric perforation secondary to recurrent trichobezoar. Indian J Pediatr 63: 689-691.

37. Kawoosa NU, Zargar BR (2011) A Giant Trichobezoar Causing Rapunzel Syndrome in a 12-year-old Female. Indian J Psychol Med 33: 77-79. 
Citation: Azeem M El-Mazary A, Ahmed FM, Hasanin A, Abdel-Hamed WM (2014) Rapunzel Syndrome in a 7-year-old Egyptian Girl with Primary Biliary Cirrhosis: A case Report and Literature Review. J Psychiatry 17: 1000155. doi:10.4172/2378-5756.1000155

Page 5 of 5

38. Pérez E, Sántana JR, García G, Mesa J, Hernández JR, et al. (2005) [Gastric perforation due to trichobezoar in an adult (Rapunzel syndrome)]. Cir Esp 78: 268-270.

39. De Backer A, Van Nooten V, Vandenplas Y (1999) Huge gastric trichobezoar in a 10-year-old girl: case report with emphasis on endoscopy in diagnosis and therapy. J Pediatr Gastroenterol Nutr 28: 513-515.

40. Fraser JD, Leys CM, St Peter SD (2009) Laparoscopic removal of a gastric trichobezoar in a pediatric patient. J Laparoendosc Adv Surg Tech A 19: 835-837.

41. Dorn HF, Gillick JL, Stringel G (2010) Laparoscopic intragastric removal of giant trichobezoar. JSLS 14: 259-262.

42. Fallon SC, Slater BJ, Larimer EL, Brandt ML, Lopez ME (2013) The surgical management of Rapunzel syndrome: a case series and literature review. J Pediatr Surg 48: 830-834.

43. Memon SA, Mandhan P, Qureshi JN, Shairani AJ (2003) Recurrent Rapunzel syndrome - a case report. Med Sci Monit 9: CS92-94.
44. Azrin NH, Nunn RG, Frantz SE (1980) Treatment of hairpulling: A comparative study of habit reversal and negative practice training. J Behav Ther Exp Psychiatry 11: 13-20.

45. Diefenbach GJ, Reitman D, Williamson DA (2000) Trichotillomania: a challenge to research and practice. Clin Psychol Rev 20: 289-309.

46. Stewart RS, Nejtek VA (2003) an open-label, flexible-dose study of olanzapine in the treatment of trichotillomania. J Clin Psychiatry 64: 49-52.

47. Swedo SE, Leonard HL, Rapoport JL, Lenane MC, Goldberger EL, et al. (1989) A double-blind comparison of clomipramine and desipramine in the treatment of trichotillomania (hair pulling) $\mathrm{N}$ Engl J Med 321: 497-501.

48. Beuers U (2006) Drug insight: Mechanisms and sites of action of ursodeoxycholic acid in cholestasis. Nat Clin Pract Gastroenterol Hepatol 3: 318-328.

49. Simonetto DA, Shah VH1, Kamath PS2 (2014) Primary prophylaxis of variceal bleeding. Clin Liver Dis 18: 335-345. 